\title{
RADIO ASTRONOMY AND THE CCIR
}

\author{
VERNON PANKONIN \\ National Science Foundation, Division of Astronomical Sciences \\ Washington, DC 20550 U.S.A.
}

\begin{abstract}
The International Radio Consultative Committee (CCIR) is a permanent organization within the International Telecommunication Union (ITU). The purpose of the CCIR is to provide technical advice to the ITU and its various organs and members on the characteristics of the radio services which are governed by the International Radio Regulations, a product of the ITU. This is accomplished through reports and recommendations which may result from the regularly scheduled meetings of the CCIR or from meetings convened to prepare for a special event such as an upcoming World Administrative Radio Conference (WARC). The CCIR is divided into Study Groups. Study Group 2 covers Space Research and Radioastronomy. This paper describes the interactions of radio astronomers with Study Group 2. The radio astronomy related Study Questions currently before this Study Group are delineated, and the nature of the active reports and recommendations are discussed.
\end{abstract}

\section{CCIR: ORGANIZATION AND PROCEDURES}

The International Telecommunication Union (ITU) is a specialized agency of the United Nations with headquarters in Geneva, Switzerland. The Union's aim is to improve and extend telecommunication services of all kinds, making them generally available to all countries and to all members of the public. Member countries collectively are the ITU, and there are currently about 160 member countries.

The ITU has the following organization: the Plenipotentiary Conference, which is the supreme organ of the Union; the Administrative Conferences; the Administrative Council; and the permanent organs of the Union, which are: the General Secretariat, the International Frequency Registration Board (IFRB), the International Radio Consultative Committee (CCIR), and the International Telegraph and Telephone Consultative Committee (CCITT).

The International Consultative Committees (CCI) are attended not only by countries that are members of the Union, but also by recognized private operating agencies and by scientific or industrial organizations that are concerned with telecommunications questions. Each CCI has a director who is assisted by a specialized secretariat. Each CCI comprises a number of Study Groups, each of which deals with a particular aspect of telecommunications. The Study Groups examine Questions which have been submitted by the Plenipotentiary Conference, by Administrative Conferences, by the 
Administrative Council, by another CCI, by the IFRB, by the Plenary Assembly of the CCI, or by at least twenty Members of the Union. The Study Groups hold interim and final meetings at which Reports and Recommendations relating to the Questions are treated. The Reports and Recommendations are presented to a Plenary Assembly of the CCI which meets about every four years. It should be emphasized that the CCIs do not prepare regulations. They draw up Recommendations and Reports on technical, operating, and tariff questions, many of which, however, form the basis subsequently for proposals by Members of the Union for revision of the Telegraph and Telephone Regulations or the Radio Regulations at World Administrative Conferences. Special meetings of a $\mathrm{CCI}$ or of a Study Group within a CCI are often convened in advance of a World Administrative Conference to compile the technical bases for the workings of the upcoming Conference.

The CCIR is the permanent organ of the ITU responsible under the International Telecommunication Convention "...to study technical and operating questions relating specifically to radiocommunications without limit of frequency range, and to issue recommendations on them..." (International Telecommunication Convention, Nairobi 1982, First Part, Chapter 1, Art. 11, No. 83). The objectives of the CCIR are in particular: (a) to provide the technical bases for use by administrative radio conferences and radiocommunication services for efficient utilization of the radio-frequency spectrum and the geostationary-satellite orbit, bearing in mind the needs of the various radio services; (b) to recommend performance standards for radio systems and technical arrangements which assure their effective and compatible interworking in international telecommunications; (c) to collect, exchange, analyze, and disseminate technical information resulting from studies by the CCIR, and other information available, for the development, planning and operation of radio systems, including any necessary special measures required to facilitate the use of such information in developing countries. The CCIR is subdivided into eleven Study Groups as indicated in Table 1.

\section{TABLE I CCIR STUDY GROUPS}

$\begin{aligned} & \text { I } \text { spectrum utilization, monitoring } \\ & \text { II } \text { space research \& radioastronomy services } \\ & \text { III fixed services below about } 30 \mathrm{MHz} \\ & \text { IV } \text { fixed services using satellites } \\ & \text { V propagation in non-ionized media } \\ & \text { VI } \text { ionospheric propagation } \\ & \text { VII } \text { standard frequency \& time-signal services } \\ & \text { VIII mobile services } \\ & \text { IX fixed services using radio-relay systems } \\ & \text { X sound broadcasting service } \\ & \text { XI television broadcasting service }\end{aligned}$


Study Group 2 of the CCIR deals with the subjects of Space Research and Radioastronomy. The terms of reference of Study Group 2 are to study questions relating to: (1) systems for the space research service, the Earth exploration-satellite service, including the meteorological-satellite service and their associated technologies, as well as general principles of systems for the operation of spacecraft; and (2) systems for the radioastronomy service and for radar astronomy, with particular reference to associated interference problems. The Study Group is subdivided into seven working groups as indicated in Table 2. About twenty countries regularly send delegations to the meetings of Study Group 2.

\section{TABLE II STUDY GROUP 2 WORKING GROUPS}

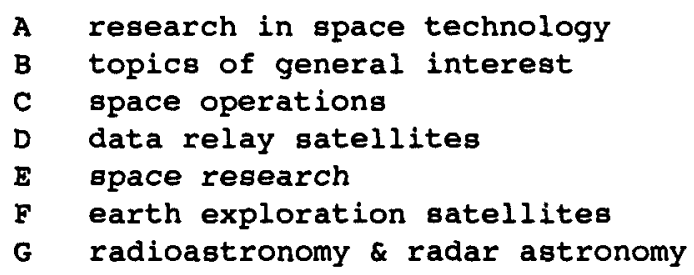

For the radiocommunication services covered by Study Group 2 there is an effort to logically separate the basic treatment of each service into the following standard set of topics: (a) the characteristics of the service, (b) preferred frequencies for operation of the service, (c) criteria for protecting the service from harmful interference, and (d) sharing frequency bands with other services. Topic (a) provides a general insight into the service, (b) is of special significance at conferences competent to change frequency allocations, and (c) and (d), while relevant to conferences, also provide information needed for special engineering studies, especially when sharing problems arise.

\section{RADIO ASTRONOMY AND THE CCIR}

Radio astronomy was accorded official international recognition as a radio service by a World Administrative Radio Conference (WARC) in 1959. Radio astronomy and the radio astronomy service were defined in the Radio Regulations, and token space was provided in the Table of Frequency Allocations. The first radio astronomy related documentation in the CCIR dates to 1953. The Plenary Assembly that year approved a recommendation on the protection of frequencies used for radio astronomical measurements.

There are currently (XVIth Plenary Assembly, Dubrovnik, 1986) three Questions and two Study Programmes in Study Group 2 which form the bases for 
all of the radio and radar astronomy related Reports and Recommendations. They are:

Question 5/2: TECHNICAL FACTORS INVOLVED IN THE PROTECTION OF RADIOASTRONOMICAL OBSERVATIONS;

Study Programme 5A/2: CRITERIA FOR EVALUATION OF INTERFERENCE TO RADIOASTRONOMY;

Question 6/2: RADAR ASTRONOMY;

Question 7/2: FREQUENCY UTILIZATION ABOVE THE IONOSPHERE AND ON THE FAR SIDE OF THE MOON;

Study Programme 7B/2: SHIELDING EFFECTS DUE TO THE MOON.

According to Question 5/2, which is the principal CCIR Question relating to radio astronomy, the following questions should be studied:

1. what are the general areas of interest in the radio-frequency spectrum to the radioastronomy service;

2. what are the characteristics of radioastronomical sources and observational techniques;

3. what are the factors which affect the practicability of frequency sharing between radioastronomy and other radio services; and

4. in what ways can radioastronomy observations be affected by spurious and other out-of-band emissions from radio transmitters located in other frequency bands and by other electrical equipment?

Study Programme 5A/2 expands on some of these questions to specify that the following studies should be carried out:

1. the practical interpretation for the radioastronomy service, of harmful interference as defined in No. 163 of the Radio Regulations;

2. the threshold levels of unwanted signals which, if exceeded for more than specified percentages of time, will cause harmful interference, and the dependence of the criteria on the nature of the radioastronomical observations;

3. the levels of interference which may occur at typical observatory sites, due to various sources of interference, including transmissions within bands used for radioastronomy observations, harmonics, intermodulation products, and sidebands from transmitters in other frequency bands; and other sources of electrical interference including Industrial, Scientific, and Medical equipment;

4. the influence of reflections from aircraft and earth satellites in increasing the risk of interference;

5. the response of typical radioastronomy receivers to signals in frequency bands adjacent to the nominal receiver acceptance band; and

6. the special precautions which may be necessary, on the part of radio astronomers and the operators of the other services, when a transmitter which is a potential source of interference is in a spacecraft or an aircraft within the field of a radioastronomical observatory. 
The Reports and Recommendations contained in the radio astronomy section of the report of Study Group 2 from the XVIth Plenary Assembly (1986) are:

Report 852: CHARACTERISTICS OF THE RADIO ASTRONOMY SERVICE AND PREFERRED FREQUENCY BANDS (Question $5 / 2)$

Report 699: IONOSPHERIC LIMITATIONS TO GROUND-BASED RADIOASTRONOMY BELOW $20 \mathrm{MHz}$ (Question 5/2);

Report 224: INTERFERENCE PROTECTION CRITERIA FOR THE RADIOASTRONOMY SERVICE (Question 5/2 and Study Programme $5 \mathrm{~A} / 2$;

Report 696: FEASIBILITY OF FREQUENCY SHARING BETWEEN RADIOASTRONOMY AND OTHER SERVICES (Question 5/2 and Study Programme 5A/2);

Report 697: INTERFERENCE TO THE RADIOASTRONOMY SERVICE FROM TRANSMITTERS IN OTHER BANDS (Question $5 / 2$ and Study Programme 5A/2);

Report 853: THE EFFECT OF A POWER SATELLITE SYSTEM UPON GROUND-BASED RADIOASTRONOMY AND RADAR ASTRONOMY (Question 5/2 and Study Programme 5A/2);

Report 854: INTERFERENCE TO RADIOASTRONOMY FROM MICROWAVE OVENS OPERATING IN THE $2450 \mathrm{MHz}$ ISM BAND (Question 5/2);

Report 539: THE PROTECTION OF RADIOASTRONOMY OBSERVATIONS IN THE SHIELDED ZONE OF THE MOON (Question 7/2);

Report 226: FACTORS AFFECTING THE POSSIBILITY OF FREQUENCY SHARING BETWEEN RADAR ASTRONOMY AND OTHER SERVICES.

Recommendation 314: PROTECTION FOR FREQUENCIES USED FOR RADIOASTRONOMICAL MEASUREMENTS (Question 5/2);

Recommendation 611: PROTECTION OF THE RADIOASTRONOMY SERVICE FROM SPURIOUS EMISSIONS (Question 5/2 and Study Programme 5A/2);

Recommendation 517: PROTECTION OF THE RADIOASTRONOMY SERVICE FROM TRANSMITTERS IN ADJACENT BANDS;

Recommendation 479: PROTECTION OF FREQUENCIES FOR RADIOASTRONOMICAL MEASUREMENTS IN THE SHIELDED ZONE OF THE MOON (Question 7/2).

Those Reports and Recommendations which address Question 5/2 in a general sense are summarized below. The dates in parenthesis signify those CCIR Plenary Assemblies at which revisions to the Report or Recommendation were made. 
Report 852 (1982) Characteristics of the radioastronomy service and preferred frequency bands

This report describes, in general terms, the science of radio astronomy. The origin and nature of cosmic emissions at radio wavelengths are discussed, using the categories of continuum emission, spectral line radiation, and bursts, pulsars and variable sources. The frequency considerations are treated in some detail with a justification for the preferred frequency bands for continuum radiation and for spectral lines.

[This report is being revised significantly in the current cycle (XVII). The principal change is to remove some historical material and thus shorten the text.]

Report 224 (1963-1966-1970-1974-1978-1982-1986) Interference protection criteria for the radioastronomy service

This is considered by radio astronomers to be the service's most important report in the CCIR literature. It first appeared in 1963, but it has undergone a number of revisions in subsequent CCIR cycles.

The report presents the formulation from which the sensitivity of a radio astronomy system is calculated. From these equations, harmful interference levels are calculated, and the results are tabulated. These harmful interference levels are presented in several different units; i.e. input power, power flux density, and spectral power flux density. The results are regarded as the general interference criteria for high sensitivity radio astronomy observations. The report also describes, briefly, a few interference reduction techniques.

Report 696 (1978-1982-1986) Feasibility of frequency sharing between radioastronomy and other services

As the title suggests this is the report which covers in some detail the sharing of a given frequency band between radio astronomy and active transmitting services. The report looks at the sharing question in general and in qualitative terms. It presents the basic relations used for calculating the geographical separation between transmitter and radio astronomy antenna which is needed for sharing to succeed. The report then treats sharing with transmitters within the line of sight of the radio astronomy antenna, and sharing with terrestrial services located beyond the horizon. Then follows a detailed discussion of sharing with typical co-allocated services in each radio astronomy band below $40 \mathrm{GHz}$.

Report 697 (1978-1982-1986) Interference to the radioastronomy service from transmitters in other bands

This report is based on the fact that as a consequence of the sensitivity of radio astronomy observations, interference can occur from transmitters which do not share the same band. This can be classified as band-edge interference and 
interference from harmonic and intermodulation signals. The report describes the role of the transmitter in the production of interference. It further presents tabulations of services in adjacent bands which could cause harmful interference to the radio astronomy service and of services which could cause harmonic interference to the radio astronomy service. One annex presents the effects of spurious emissions by geostationary satellites upon radio astronomy. A second annex describes emission measurements of the ATS-6 satellite in the 2960-2700 $\mathrm{MHz}$ radio astronomy band. A third describes steps to suppress interference to radio astronomy from out-of-band radiation from a Japanese meteorological satellite.

Recommendation 314 (1953-1956-1959-1966-1970-1974-1978-1982-1986) Protection for frequencies used for radioastronomical measurements

This is the most important CCIR recommendation for the radio astronomy service. Although it first appeared in 1953, it has undergone very significant revisions at practically every Plenary Assembly since. The 1963 version requested protection for three spectral lines -- deuterium, 21-cm HI, and 1667 $\mathrm{MHz} \mathrm{OH}$-- whereas the 1986 version lists 42 atomic and molecular lines as of the greatest importance to radio astronomy at frequencies below $275 \mathrm{GHz}$. It is now the practice of radio astronomers to carefully review this list before each triennial General Assembly of the International Astronomical Union and to convey the results of that review to the CCIR. The listing is then changed accordingly. The Recommendation also requests protection for a series of frequency bands used primarily for continuum observations.

Recommendation 611 (1986) Protection of the radioastronomy service from spurious emissions

This recommendation is new, and it acknowledges the susceptibility of radio astronomy observations to spurious emissions from transmitters, particularly those located on aircraft or spacecraft. Spurious emissions occur outside the necessary bandwidth of the transmitter and include harmonic emissions, parasitic emissions, intermodulation products, and frequency conversion products. This recommendation also introduces the objective of the radio astronomy service to be free of harmful interference from spurious emissions when observing at 5 degrees or more from satellites in a geostationary orbit.

Recommendation 517 (1978-1982) Protection of the radioastronomy service from transmitters in adjacent bands

This recommendation acknowledges the less than ideal emission characteristics of transmitters. It specifies the need to employ filters, and other practical technical means, on radio astronomy receivers and on transmitters to protect radio astronomy observations from transmitters operating in bands adjacent to a radio astronomy band. 
The Reports and Recommendations summarized above can be considered the basic documentation of the radio astronomy service in the CCIR. From time to time special situations arise which require the visibility of a separate report. An example is Report 854 on interference from microwave ovens. This type of report will probably continue to be carried in the current CCIR literature only so long as the situation is deemed a special problem.

Radio astronomers have been fairly successful in getting the requirements of their service into the CCIR literature. They have established criteria by which transmissions are considered to be "harmful interference" to radio astronomy observations. They have particularly noted the susceptibility of radio astronomy to the unwanted emissions from transmitters (the term "unwanted emissions" is defined in the Radio Regulations). Special attention is called to problems caused by transmitters located on aircraft and spacecraft because the benefit of remote siting and terrain shielding for observatories is negated. But use of the radio spectrum is undergoing revolutionary growth, and there are new techniques and uses which cause concern among radio astronomers. Digital techniques in radio transmitter equipment offer great technological advantages, but they often produce unwanted modulation products. Spread spectrum techniques can result in a general increase in the noise level in a frequency band which may not seriously impact the typical radio communications service, but which may have a very detrimental effect on radio astronomy. Broadcasting satellites which are designed to serve small communities or individual homes could be very troublesome to radio astronomers. They broadcast a relatively powerful signal so that the reception antennas on Earth can be simple and cheap, and they are often designed to serve the same types of locale which would also be chosen, because of isolation, for a radio observatory site.

The basic groundwork for regulatory protection of radio astronomy observations has been laid, but radio astronomers must be continually alert to impacts from new technologies or significant expansion of current technology. It must be understood that radio astronomy is a dynamic field of basic science. It has requirements for operation which evolve with time just as the requirements of all of the radio communications services evolve. If the purposes of the ITU are adhered to, then radio astronomy should be able to coexist with transmitting radio services. 